\title{
VOCl as Cathode for Rechargeable Chloride Ion Batteries
}

\author{
Ping Gao, ${ }^{a}$ M. Anji Reddy, ${ }^{a}$ Xiaoke Mu, ${ }^{a, b}$ Thomas Diemant, ${ }^{\mathrm{c}}$ Le Zhang, ${ }^{\mathrm{a}}$ Zhirong Zhao-Karger, ${ }^{\mathrm{b}}$ Venkata Sai \\ Kiran Chakravadhanula, ${ }^{a, b}$ Oliver Clemens ${ }^{b, d}$ R. Jürgen Behm, ${ }^{a, c}$ and Maximilian Fichtnere, b,
}

\begin{abstract}
A novel room temperature rechargeable battery with $\mathrm{VOCl}$ cathode, $\mathrm{Li}$ anode and chloride ion transporting liquid electrolyte is described here. The cell is based on the reversible transfer of chloride ions between the two electrodes. The $\mathrm{VOCl}$ cathode delivered an initial discharge capacity of $189 \mathrm{mAh} \mathrm{g}^{-1}$. A reversible capacity of $113 \mathrm{mAh} \mathrm{g}^{-1}$ was retained even after 100 cycles when cycled at a high current density of $522 \mathrm{~mA} \mathrm{~g}^{-1}$. For the first time such high cycling stability was achieved in chloride ion batteries demonstrating the practicality of system beyond the proof-of-concept The electrochemical reaction mechanism of the $\mathrm{VOCl}$ electrode in the chloride ion cell was investigated in detail by ex-situ X-ray diffraction (XRD), infrared spectroscopy (FTIR), transmission electron microscopy (TEM) and X-ray photoelectron spectroscopy (XPS). The result confirms reversible deintercalation/intercalation of chloride ions in the $\mathrm{VOCl}$ electrode.
\end{abstract}

Recently, a novel rechargeable battery has been demonstrated based on chloride shuttle at room temperature. ${ }^{[1]}$ Selected electrochemical couples of this chloride ion battery (CIB) offer theoretical energy densities up to a value of $2500 \mathrm{Wh} \mathrm{L}^{-1} .^{[1,2]}$ In principle, various metals with low reduction potential such as $\mathrm{Li}$, $\mathrm{Mg}, \mathrm{Ca}$ can be used as anode materials for this system. In our previous study, $\mathrm{Li}$ and $\mathrm{Mg}$ metals were used as anodes for chloride ion battery cells with different cathode materials. ${ }^{[1-4]}$ In the first study of a CIB by Zhao et al., ${ }^{[1]}$ using $\mathrm{BiCl}_{3}, \mathrm{VCl}_{3}$ and $\mathrm{CoCl}_{2}$ cathodes, the proof-of-principle was demonstrated and these electrodes exhibited an interesting electrochemical performance for the rechargeable batteries. Also metal oxychlorides such as $\mathrm{FeOCl}, \mathrm{BiOCl}$ and $\mathrm{VOCl}$ have been proposed as potential cathode materials for the CIBs. ${ }^{[2-4]}$ The cathodic and anodic reactions of the CIB during discharge process can be described as follows:

At the cathode: $\mathrm{MCl} x+x \mathrm{e}^{-} \leftrightarrow \mathrm{M}+x \mathrm{Cl}^{-}$

at the anode: $\mathrm{M}^{\prime}+x \mathrm{Cl}^{-} \leftrightarrow \mathrm{M}^{\prime} \mathrm{Cl} x+x \mathrm{e}^{-}$,

where $\mathrm{M}$ is the metal (e.g. Fe, $\mathrm{Bi}$ or $\mathrm{V}$ ) or metal monoxide (FeO, $\mathrm{BiO}$ or $\mathrm{VO}$ ) used as cathode and $\mathrm{M}^{\prime}$ is highly electropositive

[a] P. Gao, Dr. M. A. Reddy, Dr. X. Mu, L. Zhang, Dr. S. K. Chakravadhanula, Prof. Dr. R. J. Behm, Prof. Dr. M. Fichtner

Department Helmholtz Institute Ulm for Electrochemical Energy Storage (HIU), Helmholtzstr.11, D-89081 Ulm, Germany

E-mail: m.fichtner@kit.edu Tel:+49(0)731 5034201. Fax: +49(0)721 6086368 (M.F.).

[b] Dr. X. Mu, Dr. Z. Z. Zhao-Karger, Dr. S. K. Chakravadhanula, Dr. O. Clemens, Prof. Dr. M. Fichtner

Institute of Nanotechnology, Karlsruhe Institute of Technology (KIT), P.O.Box 3640, D-76021 Karlsruhe, Germany

[c] Dr. T. Diemant, Prof. Dr. R. J. Behm Institute of Surface Chemistry and Catalysis, Ulm University, Albert-EinsteinAllee 47, D-89081 Ulm, Germany

[d] Dr. O. Clemens

Joint Research Laboratory Nanomaterials, Jovanka-Bontschits-str. 2, Darmstadt University of Technology, D-64287 Darmstadt, Germany

Supporting information for this article is given via a link at the end of the document metals (e.g. $\mathrm{Li}, \mathrm{Mg}$ or $\mathrm{Ca}$ ) used in the anode. One issue in the first CIB that has been recognized was the dissolution of certain metal chlorides in the electrolyte, which could cause a poor electrochemical performance. The investigation of CIB currently focuses on the exploration of potential electrodes or electrode combinations with high reversibility as well as compatible electrolytes. Ionic liquids were used as electrolytes in previous studies, but also other non-aqueous electrolytes based on carbonate solvent can be used in CIBs, as will be shown. In the following, we report a novel room temperature chloride ion battery ( $\mathrm{Li} / \mathrm{PP}_{14} \mathrm{Cl}-\mathrm{PC} / \mathrm{VOCl}$ ) by using a $\mathrm{VOCl}$ electrode as cathode, lithium metal as anode, and a solution of $0.5 \mathrm{M} 1$-butyl1-methylpiperidinium chloride $\left(\mathrm{PP}_{14} \mathrm{Cl}\right)$ in propylene carbonate (PC) as an electrolyte. In addition, the electrochemical results of $\mathrm{Li} / \mathrm{PP}_{14} \mathrm{Cl}-\mathrm{PC} / \mathrm{VOCl}$ cell was compared with that of a $\mathrm{Li}$ ion cell built with the same cathode and anode, but with a $\mathrm{LiPF}_{6}$ based electrolyte.

$\mathrm{VOCl}$ was synthesized by a solid-gas reaction as described in previous work. ${ }^{[4]}$ Typical synthesis was done by heating a 1:1.8 molar ratio of $\mathrm{V}_{2} \mathrm{O}_{3}\left(98 \%\right.$, Sigma-Aldrich) and $\mathrm{VCl}_{3}(97 \%$, Sigma-Aldrich) in an evacuated and sealed quartz tube kept at a temperature of $893 \mathrm{~K}$ for $120 \mathrm{~h}$ with a heating rate of $1 \mathrm{~K} \mathrm{~min}^{-1}$. The resulting brown $\mathrm{VOCl}$ material was washed with water and acetone to remove the residual $\mathrm{VCl}_{3}$. The layered $\mathrm{VOCl}$ crystallizes in an orthorhombic structure with a space group of Pmmn (lattice parameter: $a=3.78 \AA$, $b=3.30 \AA, c=7.91 \AA$ ). ${ }^{[5]}$ The buckled $\mathrm{V}-\mathrm{O}$ bilayer is sandwiched between chlorine layers which are weakly coupled through van der Waals forces along the crystallographic $c$ direction. ${ }^{[6]}$

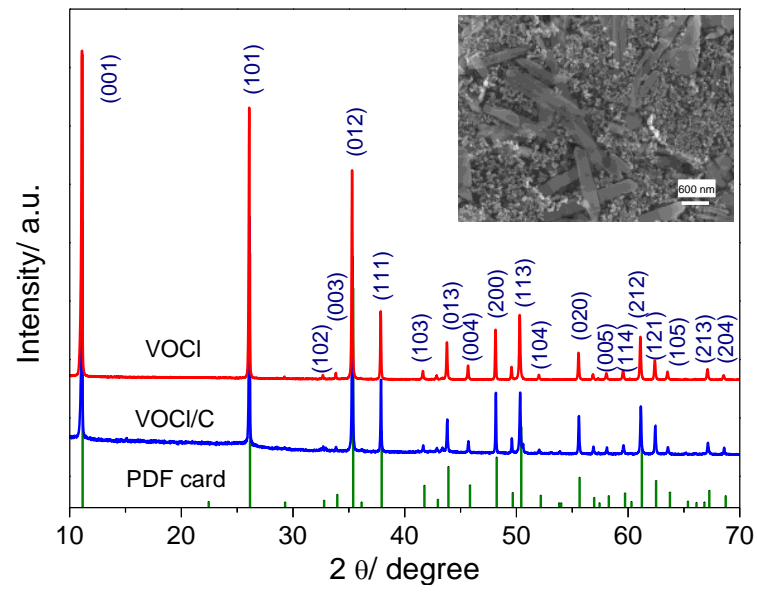

Figure 1. XRD patterns of $\mathrm{VOCl}$ and $\mathrm{VOCl} / \mathrm{C}$ composite, (inset) SEM image of the $\mathrm{VOCl} / \mathrm{C}$ composite. For a plot of the Rietveld analysis, see the Supporting Information (Figure S1 and Figure S2).

The XRD pattern of the as synthesized $\mathrm{VOCl}$ is given in Figure 1 . All peaks matched well with the $\mathrm{VOCl}$ reference pattern from 
PDF card no. 01-074-1274. In addition, we found small amounts of impurity phases of $\mathrm{V}_{2} \mathrm{O}_{3}(\sim 2 \mathrm{wt} \%), \mathrm{VCl}_{2}(\sim 1$ wt \%), and, presumably, an fcc metal, which were found to be unaffected by subsequently performed discharging / charging cycles (Figure S2) showing their electrochemical inactivity. Figure S3 shows the SEM images of as-synthesized VOCl particles. They exhibit a rod shape morphology with a length of $2-5 \mu \mathrm{m}$ and $\sim 300 \mathrm{~nm}$ diameter. As $\mathrm{VOCl}$ is a semiconductor, ${ }^{[7-9]}$ it was mixed with carbon black as conducting additive using mortar and pestle in order to provide good electrical contact of $\mathrm{VOCl}$ in the electrode. The inset in Figure 1 shows that the $\mathrm{VOCl}$ particles were homogenously dispersed in the carbon black, and they retained the same morphology and particle size as the pure $\mathrm{VOCl}$ material shown in Figure S3.
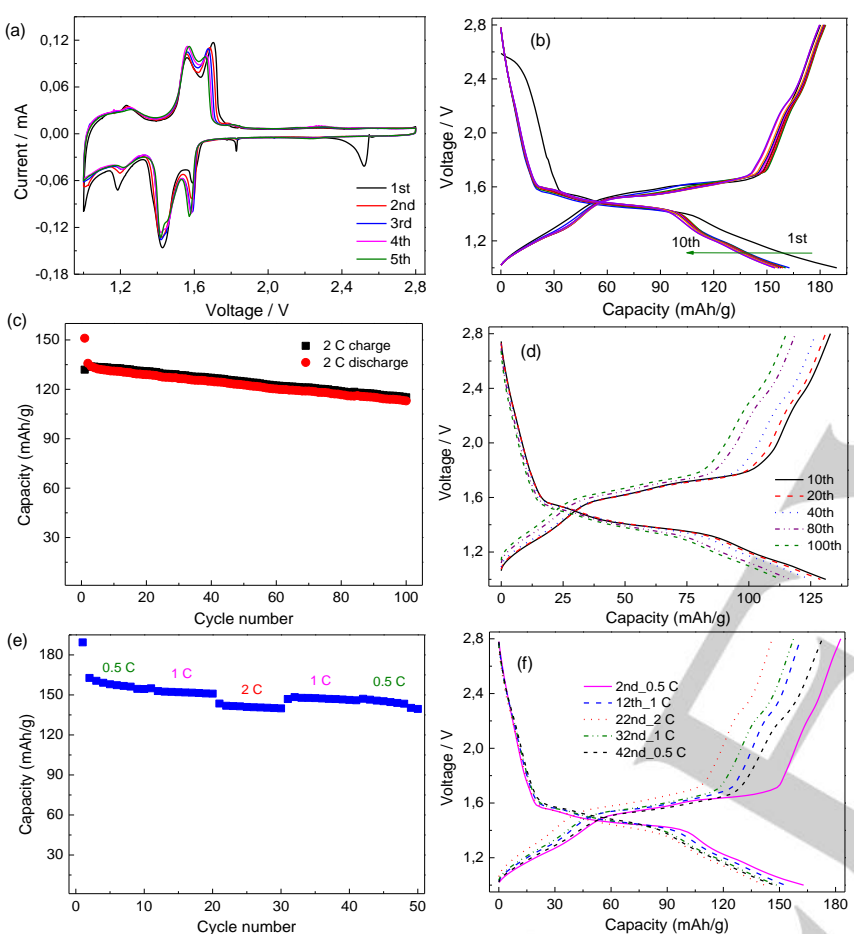

Figure 2. (a) $\mathrm{CV}$ curves of $\mathrm{Li} / \mathrm{PP}_{14} \mathrm{Cl}-\mathrm{PC} / \mathrm{VOCl}$ cell at a scan rate of $0.1 \mathrm{mV}$ $\mathrm{s}^{-1}$, (b) initial charge/discharge curves of the cell at $0.5 \mathrm{C}$ in the voltage range of $1.0-2.8 \mathrm{~V}$. Cycling performance at $2 \mathrm{C}(\mathrm{c}, \mathrm{d})$ and rate performance $(e, f)$ of the $\mathrm{Li} / \mathrm{PP}_{14} \mathrm{Cl}-\mathrm{PC} / \mathrm{VOCl}$ cell.

The liquid electrolyte of $\mathrm{PP}_{14} \mathrm{Cl}-\mathrm{PC}(0.5 \mathrm{M})$ prepared in this study has a high ionic conductivity of $4.4 \mathrm{mS} \mathrm{cm}^{-1}$ with an electrochemical window of $3.2 \mathrm{~V}$ versus lithium metal measured at room temperature (Figure S4), which is enough to provide a stable environment for the electrochemical reaction. The initial $\mathrm{CV}$ curves of $\mathrm{Li} / \mathrm{PP}_{14} \mathrm{Cl}-\mathrm{PC} / \mathrm{VOCl}$ cell scanned at $0.1 \mathrm{mV} \mathrm{s}^{-1}$ in the voltage range of $1.0-2.8 \mathrm{~V}$ and $0.5-3.0 \mathrm{~V}$ are shown in Figure $2 \mathrm{a}$ and Figure S5, respectively. Three main redox couples were observed at $1.57 / 1.67 \mathrm{~V}, 1.42 / 1.56 \mathrm{~V}$, and 1.2/1.26 $\mathrm{V}$ in a voltage range of 1.0-2.8 $\mathrm{V}$, which indicates a multi-step reaction proceeding during the discharge and recharge process. A structural model for such stepwise behavior reaction is proposed in the supporting information. In the subsequent cycle,
CV curves were similar to that of the first one, which demonstrates the reversibility of the electrochemical process. In addition, an irreversible anodic peak was observed at around 2.5 $\mathrm{V}$ in the first cycle. The origin of this peak will be discussed below. Figure $2 \mathrm{~b}$ shows the discharge and charge curves of the $\mathrm{Li} / \mathrm{PP}_{14} \mathrm{Cl}-\mathrm{PC} / \mathrm{VOCl}$ cell for the first 10 cycles obtained at a rate of $0.5 \mathrm{C}\left(1 \mathrm{C}=261 \mathrm{~mA} \mathrm{~g}^{-1}\right)$ at $298 \mathrm{~K}$. A small plateau was observed at $2.5 \mathrm{~V}$, then the voltage dropped monotonically to 1.7 $\mathrm{V}$ and three discharge plateaus were observed at around 1.6, 1.5 and $1.2 \mathrm{~V}$. The corresponding differential capacity plots are shown in Figure S6, giving similar peaks as observed in the CV measurement. The cell delivered a total discharge capacity of $189 \mathrm{mAh} \mathrm{g}^{-1}$ in the $1^{\text {st }}$ discharge, corresponding to 0.72 electrons per $\mathrm{VOCl}$ unit participating in the reaction. A capacity of 180 $\mathrm{mAh} \mathrm{g}^{-1}$ was recovered in the first recharge process with an irreversible capacity loss (ICL) of $9 \mathrm{mAh} \mathrm{g}^{-1}$ at $0.5 \mathrm{C}$ in the first cycle. Subsequent discharge and charge curves were similar to the first discharge and charge, indicating a high reversibility of the $\mathrm{VOCl}$ electrode in this battery.

The length of the small plateau at $2.5 \mathrm{~V}$ corresponds to a capacity of $20 \mathrm{mAh} \mathrm{g}^{-1}$, which is equivalent to 0.07 mole electron transfer. This step is attributed to the intercalation of $\mathrm{PP}_{14}$ ions from the electrolyte into the $\mathrm{VOCl}$ electrode. It was shown before that large organic cations can be intercalated into the interlayer of metal oxychlorides. ${ }^{[10-14]}$ The intercalated molecule has in fact been detected by combined XRD, FTIR and XPS measurements, which will be discussed later.
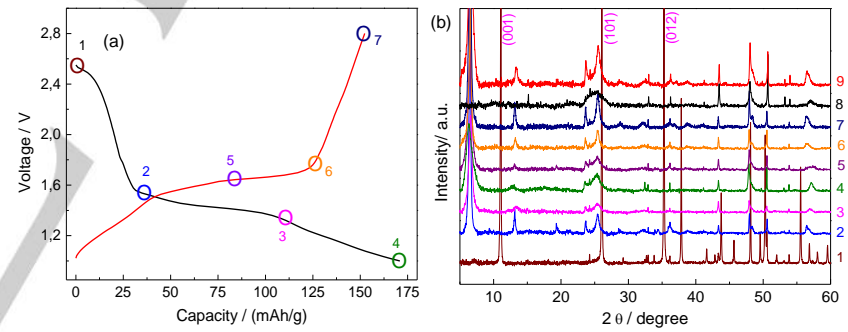

(c)
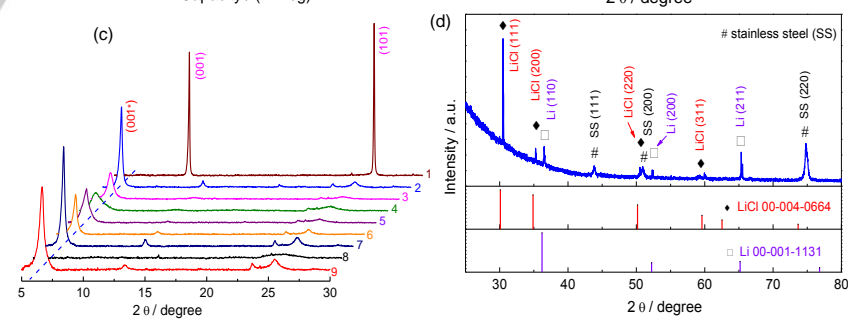

Figure 3. (a) Charge/discharge curve of the $\mathrm{VOCl}$ electrode at $1 \mathrm{C}$ in the firs cycles. The different electrochemical states at which ex-situ XRD measurement were performed are marked. (b and c) Ex-situ XRD patterns of VOCl electrode at different charge/discharge states in the $1^{\text {st }}$ cycle and $10^{\text {th }}$ cycle and (d) XRD patterns of lithium anode after the first discharge.

The cycling performance of $\mathrm{Li} / \mathrm{PP}_{14} \mathrm{Cl}-\mathrm{PC} / \mathrm{VOCl}$ operated at a current density of $2 \mathrm{C}$ is given in Figure 2c. A first discharge capacity of $151 \mathrm{mAh} \mathrm{g}^{-1}$ was obtained in the voltage range of 1.0 - $2.8 \mathrm{~V}$. Then the capacity faded to $135 \mathrm{mAh} \mathrm{g}^{-1}$ in the $2^{\text {nd }}$ cycle and a capacity of $113 \mathrm{mAh} \mathrm{g}^{-1}$ was obtained after 100 cycles with a coulombic efficiency of $98 \%$. The polarization increased slightly during the cycling as shown in Figure $2 \mathrm{~d}$. The rate 
performance of the $\mathrm{Li} / \mathrm{PP}_{14} \mathrm{Cl}-\mathrm{PC} / \mathrm{VOCl}$ battery is shown in Figure 2e. Discharge capacities of $189 \mathrm{mAh} \mathrm{g}^{-1}, 154 \mathrm{mAh} \mathrm{g}^{-1}$ and $143 \mathrm{mAh} \mathrm{g}^{-1}$ were obtained at $0.5 \mathrm{C}\left(1^{\mathrm{st}}\right), 1 \mathrm{C}\left(11^{\text {th }}\right)$ and $2 \mathrm{C}$ $\left(21^{\text {st }}\right)$ rate, respectively. After 10 cycles at $2 \mathrm{C}$, the discharge capacity of $148 \mathrm{mAh} \mathrm{g}^{-1}\left(1 \mathrm{C}, 32^{\text {nd }}\right)$ and $147 \mathrm{mAh} \mathrm{g}^{-1}\left(0.5 \mathrm{C}, 42^{\text {nd }}\right)$ can be recovered in the subsequent cycling. This demonstrates that the cell could deliver a high rate capacity combined with a decent cycling stability. The charge and discharge curves of the $\mathrm{VOCl}$ electrode cycled at different current densities are given in Figure $2 \mathrm{f}$, where a quite similar curve with slight increase of the polarization was observed at a high current density.

In order to understand the reaction mechanism of the $\mathrm{Li} /$ $\mathrm{PP}_{14} \mathrm{Cl}-\mathrm{PC} / \mathrm{VOCl}$ battery, ex-situ XRD of the $\mathrm{VOCl}$ electrode and lithium anode was performed at different electrochemical states in the $1^{\text {st }}$ and $10^{\text {th }}$ cycle to investigate the phase evolution during the electrochemical reaction (Figure 3). Figure 3a shows the discharge and charge curve of the $\mathrm{VOCl}$ electrode for the first cycle at $1 \mathrm{C}$ with seven discharged and charged states where ex-situ XRD measurements were made. In the $1^{\text {st }}$ cycle, point 1 to point 7 represent the $\mathrm{VOCl}$ electrode in the electrochemical state of as-prepared (1), discharged $1.53 \mathrm{~V}(2)$, discharged $1.33 \vee(3)$, discharged $1.0 \vee(4)$, recharged $1.62 \mathrm{~V}$ (5), recharged $1.75 \vee(6)$ and recharged $2.8 \vee(7)$, respectively. Point 8 and point 9 shown in Figure $3 \mathrm{~b}$ and $3 \mathrm{c}$ represent the discharged $1.0 \mathrm{~V}$ and recharged $2.8 \mathrm{~V}$ of the $\mathrm{VOCl}$ electrode in the $10^{\text {th }}$ cycle. Figure $3 \mathrm{~b}$ shows the full XRD pattern and Figure $3 c$ shows the selected $X R D$ patterns at low angles, respectively. After discharging to $1.53 \mathrm{~V}$ (point 2), the XRD pattern was significantly different from that of the as-prepared $\mathrm{VOCl}$ electrode, particularly in the low angle region as shown in Figure $3 \mathrm{~b}$ and $3 \mathrm{c}$. A new strong reflection evolved at $2 \theta=6.5^{\circ}$, which corresponds to a $d$ spacing value of $13.38 \AA$. Compared to the original $\mathrm{VOCl}$ with the $c$ axis spacing of $7.91 \AA$, an expansion by $5.47 \AA$ took place, which is an indication for the intercalation of 1-butyl-1-methylpiperidinium cation $\left(\mathrm{PP}_{14}{ }^{+}\right)$between the $\mathrm{VOCl}$ interlayers during the initial stage of discharge. The $\mathrm{PP}_{14}{ }^{+}$ molecule is illustrated in Figure S7, it is expected that the molecule prefers an orientation horizontal to the host. Expansion of $\mathrm{MOCl}$ layers upon intercalation of large organic cations were also noticed in other metal oxychlorides such as, FeOCl, ${ }^{[10-13]}$ $\mathrm{TiOCl}^{[14]}$ and $\mathrm{VOCl}^{\left[{ }^{14,15]}\right.}$ All further reflections at higher angles strongly decrease in intensity, which is indicative for strong increasing disorder (potentially resulting from relative torsion of neighbouring layers or buckling of layers, with relative reorientations of neighboring layers being a well-known phenomenon of this structure type). ${ }^{[12,16,17]}$ The analysis of the patterns in the charged and discharged state is provided in the supporting information. Upon further discharge to point 3 and point 4 , the reflections which must be assigned to the $\mathrm{VOCl}$ type phase show increased broadening. Interestingly, upon recharging to $2.8 \mathrm{~V}$ (point 7 ), the initial width is gradually recovered, demonstrating a topotactic nature of the electrochemical reaction (see supporting information for a more detailed explanation). In the discharge state of the $10^{\text {th }}$ cycle (Figure $3 \mathrm{~b}$ and $3 \mathrm{c}$, point 8 ), ( $\mathrm{OOI}$ ) type reflections show an extremely strong increase of broadening, with the remaining part of the pattern being rather similar to previous charge/discharge states. However, in the subsequent recharge (point 9), all peaks were recovered and the XRD pattern was in good agreement with the pattern recorded in the $1^{\text {st }}$ cycle (point 7). Again, this is in good agreement with the observed topotactic nature of the reaction, and hints at strong influences on the crystallinity/disorder within the compound by increasing the cycle number. In Figure 3(c), the sharp reflections observed in XRD patterns 2-9 belong to impurity phases (a fit of the diffraction data of point 7 is shown in Figure S8) also found for the state 1, but better visible than for diffraction pattern 1 due to the strong decrease of overall intensity.

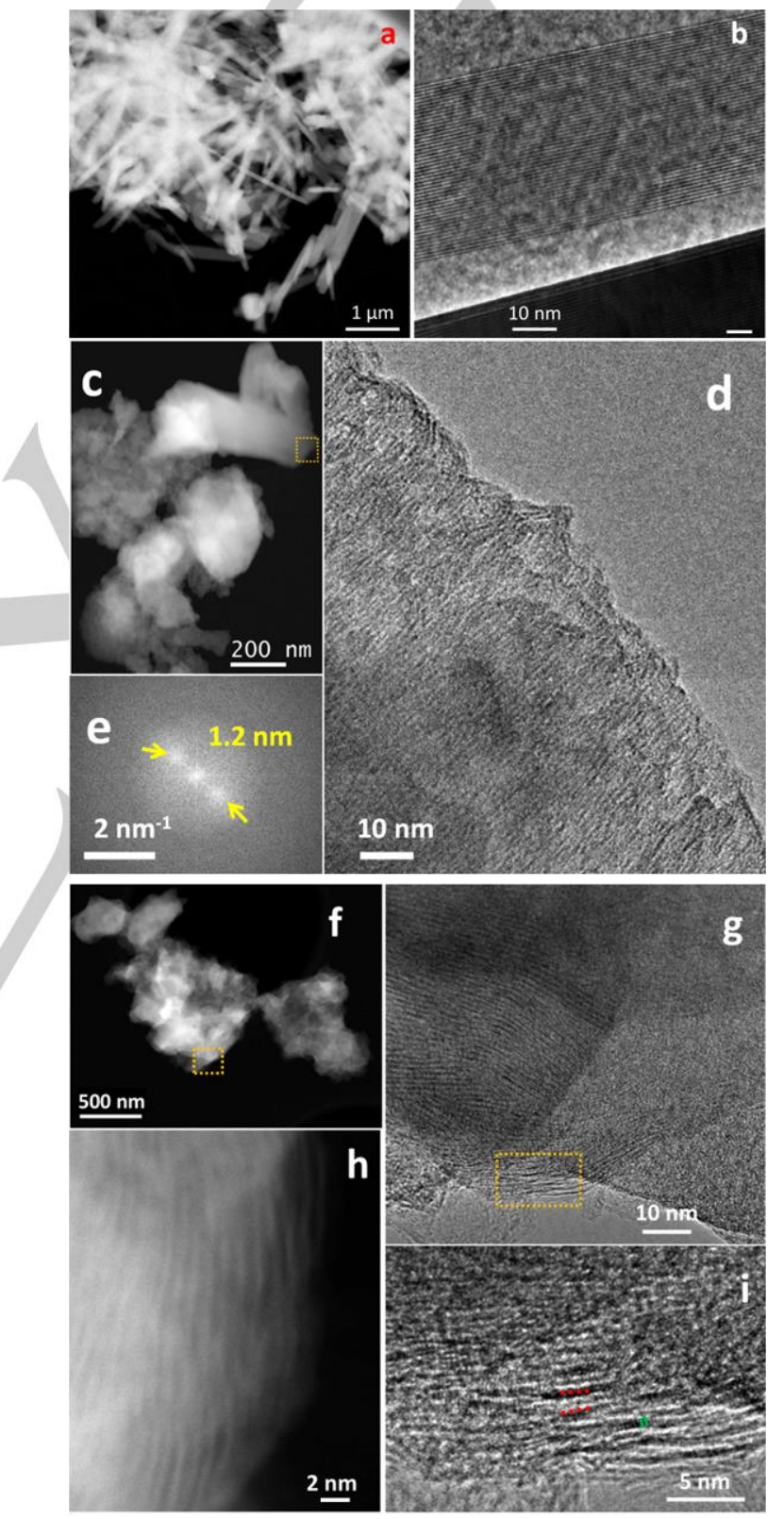

Figure 4. (a) STEM-HAADF large-area image and (b) enlarged HRTEM micrograph of the as-prepared VOCI. (c) STEM-HAADF overview image of the discharged sample, (d) low-dose HRTEM micrograph from the area indicated in $\mathrm{c}$, (e) fast Fourier transform of the HRTEM image in c, where the yellow arrows highlight the reflections corresponding to (001) vocl. (f) STEM-HAADF overview image of the recharged sample, (g) HRTEM micrograph from the area indicated in $\mathrm{f}$, (i) magnified image of marked area in $\mathrm{g}$, where the red dot- 
lines highlight distorted (001) lattices with a d-value of $\sim 1.2 \mathrm{~nm}$ (h) STEMHAADF image from the same area as i showing the distorted (001) lattices.

The lithium anode was also tested by ex-situ XRD to further understand the phase evolution in the first discharge as shown in Figure 3d. Reflections at $2 \theta=30.4^{\circ}, 35.2^{\circ}$ and $50.3^{\circ}$, related to $\mathrm{LiCl}$ (PDF card no.00-004-0664), were detected as well as the lithium phase $\left(2 \theta=36.2^{\circ}, 52.1^{\circ}\right.$ and $65.2^{\circ}$, PDF card no. 00 $001-1131)$ and the stainless steel current collector $\left(2 \theta=43.8^{\circ}\right.$, $50.9^{\circ}$ and $\left.74.9^{\circ}\right)$. This demonstrates that the lithium anode was oxidized to form $\mathrm{LiCl}$ by taking chloride ions transported through the electrolyte during the discharge. The $\mathrm{Cl} / \mathrm{V}$ ratio from the SEM-EDX spectra measured at several particles of the $\mathrm{VOCl}$ electrodes after the first cycle (Figure S9) evidences a loss and gain of chloride in the discharge and recharge process. Taken together, the voltage composition profiles and ex-situ XRD results demonstrate that the discharge and charge reaction mechanism in the first and subsequent cycles is the same.

Figure $4 a$ shows a STEM-HAADF overview image of the rodshape morphology in the as-prepared sample. The HRTEM micrograph (Figure $4 \mathrm{~b}$ ) reveals the layered structure corresponding to the van der Waals bonded (001) vocl planes. In the discharged state, the HRTEM micrograph (Figure 4d) shows layered features and the corresponding fast Fourier transformation (FFT) (Figure 4e, highlighted by the arrows) exhibits broad peaks with $1.2 \mathrm{~nm}$ lattice distance, corresponding to a distorted (001) vocl lattice, in agreement with the XRD results in Figure 3b. Figure S10 demonstrates that the discharged sample is sensitive to electron beam damage. $2 \sim 3 \mathrm{~nm}$ vanadium (III) oxide crystallites with space group of $\mathrm{Fm} 3 \mathrm{~m}$ (225) form under electron beam irradiation of the experiment (approximately $5 \times 10^{7}$ electrons $\mathrm{nm}^{-2}$ ). ${ }^{[18]}$ This result indicates the meta-stability of the layered structure in the discharged sample in contrast to the as-prepared and recharged sample. The dvalues determined from the STEM-HAADF and the HRTEM micrographs of the recharged sample (Fig. $4 \mathrm{~g}, \mathrm{~h}$ and i) correspond to the distorted reflection of the (001) voc lattice plane. The TEM mapping of the discharged and recharged $\mathrm{VOCl}$ electrodes are shown in Figure $\mathbf{S 1 1}$ and S12, respectively. Figure 5a shows EEL spectra recorded on the same area of the TEM for the as-prepared (solid, black), discharged (dash-dotted, red) and recharged (dotted, blue) samples including the $\mathrm{Cl}-\mathrm{L}$ edge at $200 \mathrm{eV}$ and the $\mathrm{V}-\mathrm{L}$ edge at $512 \mathrm{eV}$. The three (background corrected) spectra are aligned with respect to the vanadium signal. The area under the $\mathrm{Cl}-\mathrm{L}$ edge directly relates to the relative amount of $\mathrm{Cl}$ in the three samples, implying a loss and gain of chloride ions in the $\mathrm{VOCl}$ electrode during the discharge and recharge process, respectively.

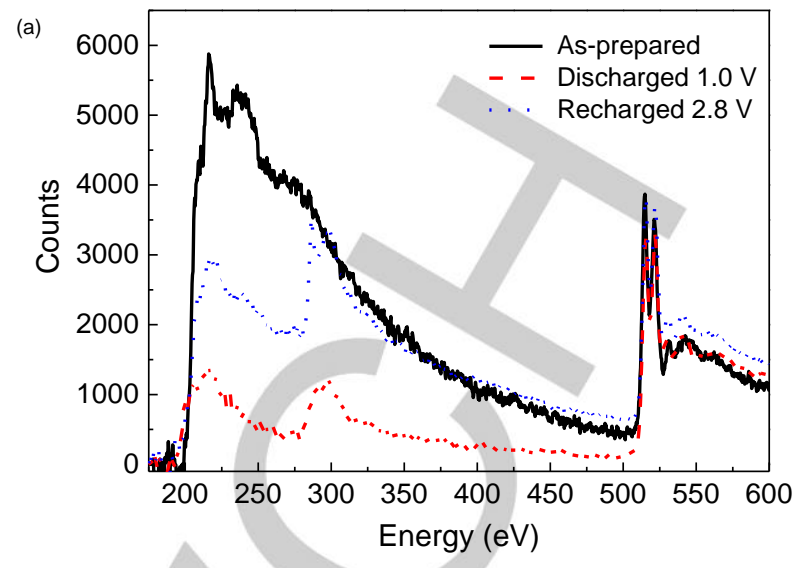

(b)

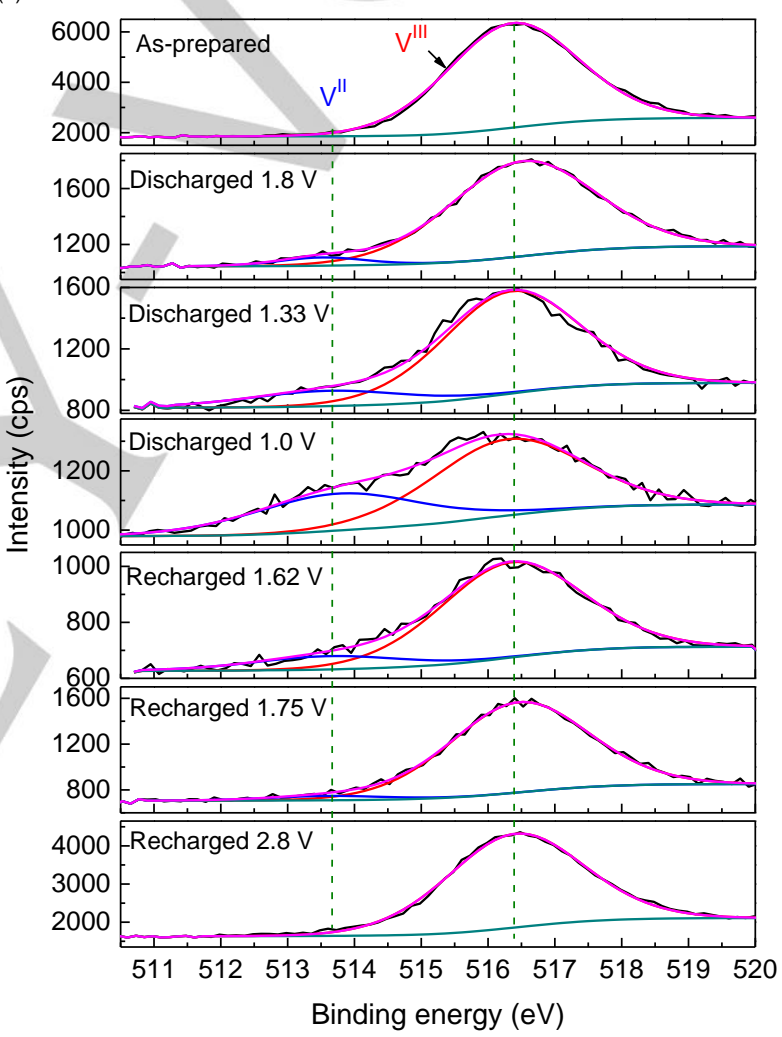

Figure 5. (a) EEL spectra of the as-prepared (black, solid line), discharged (red, dashed line) and recharged (blue, dotted line) samples. The features at $285 \mathrm{eV}$ are due to the carbon $\mathrm{K}$ edge from the binder. The spectra are vertically aligned with respect to the background subtracted vanadium peak. (b) XPS spectra in the $\mathrm{V}_{2 \mathrm{p} 3 / 2}$ region of $\mathrm{VOCl}$ electrodes in various electrochemical states.

The oxidation state of vanadium in different electrochemical states was investigated by ex-situ XPS measurements to further understand the reaction mechanism of the $\mathrm{Li} / \mathrm{PP}_{14} \mathrm{Cl}-\mathrm{PC} / \mathrm{VOCl}$. Figure $5 b$ shows the XP spectra of the $V_{2 p 3 / 2}$ regions in the asprepared, discharged to $1.8 \mathrm{~V}, 1.33 \mathrm{~V}, 1.0 \mathrm{~V}$, and recharged to $1.62 \mathrm{~V}, 1.75 \mathrm{~V}, 2.8 \mathrm{~V}$ states of the $\mathrm{VOCl}$ electrode for the $1^{\text {st }}$ cycle. The survey spectra of the electrode at these points are given in Figure S13. In the as-prepared sample, a single peak 
was observed in the $V_{2 p 3 / 2}$ region with a binding energy of 516.3 $\mathrm{eV}$, which can be ascribed to the trivalent vanadium in VOCl. ${ }^{[19]}$ Upon discharging to $1.8 \mathrm{~V}$, a new peak with a binding energy of $513.7 \mathrm{eV}$ appeared, in addition to the $\mathrm{V}_{2 \mathrm{p} 3 / 2}$ peak at $516.3 \mathrm{eV}$, which is attributed to the $V_{2 p 3 / 2}$ state in $V^{2+}$ [20] $^{20}$ The peak area attributed to $\mathrm{V}^{2+}$ (it is not large which may be due to its sensitivity on the surface) increased generally upon discharge and decreased during the recharge process again. In the recharged $\mathrm{VOCl}(2.8 \mathrm{~V})$, the lower binding energy peak disappeared and only the peak at $516.4 \mathrm{eV}$ was left, demonstrating that the $\mathrm{V}^{2+}$ was transformed back into $\mathrm{V}^{3+}$ in the recharge process. The observation of vanadium in a lower chemical valence can be ascribed to the partial reduction of $\mathrm{V}^{3+}$ to $\mathrm{V}^{2+}$, in accordance to the dissociation of chloride ions from the $\mathrm{VOCl}$ in the discharge process. After recharging, the $\mathrm{V}^{3+}$ was re-gained in $\mathrm{VOCl}$, which demonstrates a reversible oxidation-reduction process. In addition, XP spectra of the $\mathrm{Cl}_{2 p}$ region of these $\mathrm{VOCl}$ electrodes and from lithium anodes in different states are shown in Figure S14 and S15, respectively.

To gain further insight into the potential intercalation of the organic cation from $\mathrm{PP}_{14} \mathrm{Cl}$ into $\mathrm{VOCl}$, we performed additional IR, XPS, and SEM measurements. The discharged electrode was washed several times by $\mathrm{PC}$ and $\mathrm{DMC}$, to remove any precipitated $\mathrm{PP}_{14} \mathrm{Cl}$ on the surface of the electrode. Figure $\mathrm{S} 16$ shows the FTIR spectra of the PVDF, VOCl after discharge to $1.33 \mathrm{~V}$ and 1-butyl-1-methylpiperidinium chloride $\left(\mathrm{PP}_{14} \mathrm{Cl}\right)$. The FTIR of the $\mathrm{VOCl}$ in different electrochemical states and the assignment of the peaks are shown in Figure S17, S18 and Table S1. The bands at 944,2872 and $2938 \mathrm{~cm}^{-1}$ are assigned to the $\mathrm{N}-\mathrm{C}\left(\mathrm{CH}_{3}\right)$ stretching and the twisting / rocking of $\mathrm{H}-\mathrm{C}-\mathrm{H}$ in the piperidinium ring, the symmetric and asymmetric $\mathrm{C}-\mathrm{H}$ stretching in the butyl group and in the piperidinium ring, respectively. ${ }^{[21]} \mathrm{A}$ shift of the bands to lower frequency at 921 , 2866 and $2920 \mathrm{~cm}^{-1}$ was observed in charged/discharged samples which is in agreement with analogue layered material intercalated with guest molecules, ${ }^{[16]}$ suggesting the intercalation of $\mathrm{PP}_{14}$ cation in the interlayer of VOCl. Figure $\mathrm{S} 19$ shows the $\mathrm{N}_{1 \mathrm{~s}} \mathrm{XP}$ spectra of the $\mathrm{VOCl}$ electrode in the as-prepared and in the discharged to $1.8 \mathrm{~V}, 1.33 \mathrm{~V}$ and recharged to $1.62 \mathrm{~V}$, or 1.75 $\mathrm{V}$ states. The appearance of the $\mathrm{N}_{1 \mathrm{~s}}$ peak after discharging to $1.8 \mathrm{~V}$ and its persistence during recharging further demonstrates the intercalation of the $\mathrm{PP}_{14}$ cation into the $\mathrm{VOCl}$ electrode. In addition, an expansion of the layered structure of the discharged $\mathrm{VOCl}$ electrode was also observed by SEM as shown in Figure $\mathrm{S} 20$. Based on the above observations and the XRD results, we conclude that the cation of $\mathrm{PP}_{14} \mathrm{Cl}$ molecule is intercalated into the layered $\mathrm{VOCl}$ material during the initial stage of the first discharge and remains intercalated during further cycles.

Based on the electrochemical, ex-situ XRD, TEM, FT-IR and XPS analysis we postulate the following mechanism for the $\mathrm{Li} /$ $\mathrm{PP}_{14} \mathrm{Cl}-\mathrm{PC} / \mathrm{VOCl}$ cell. During the initial discharge at $2.5 \mathrm{~V}, 0.07$ mol of the $\mathrm{PP}_{14}$ cation are intercalated irreversibly into the $\mathrm{VOCl}$ electrode, leading to an expansion of the layers. For charge balancing, an equal amount of $\mathrm{Cl}^{-}$ions reacts with the anode and forms $\mathrm{LiCl}$. Upon further discharge, chloride ions are deintercalated from $\mathrm{VOCl}$, transported through the electrolyte, and react with $\mathrm{Li}$ to form $\mathrm{LiCl}$. During the recharge process the chloride ions are intercalated into the $\mathrm{VOCl}$ electrode. The intercalated $\mathrm{PP}_{14}$ cation facilitates the chloride deintercalation and intercalation process by keeping the layers wide and intact, which is evidenced by the reversible change of width of the peak at $2 \theta=6.5^{\circ}$ during discharge and charge. This could be the reason for the good reversible capacity of the electrode observed also for high current densities. The proposed reaction mechanism and the detailed explanation for the reaction are outlined in further detail in the supporting information.

It is interesting to compare the discharge profiles of the $\mathrm{Li} /$ $\mathrm{PP}_{14} \mathrm{Cl}-\mathrm{PC} / \mathrm{VOCl}$ and $\mathrm{Li} / \mathrm{LiPF}_{6}$-EC-DMC-PC / VOCl cell, the former based on chloride ion transport and the later based on lithium-ion transport, see Figure S21. The discharge and charge profiles of the cell based on lithium ion transport are completely different and give further evidence that the $\mathrm{Li} / \mathrm{PP}_{14} \mathrm{Cl}-\mathrm{PC} / \mathrm{VOCl}$ cell works by a different mechanism. However, in the chloride ion cell, the discharge product of $\mathrm{LiCl}$, even with a low solubility in PC solvent, may dissolve to a certain extent. Therefore, the interference of lithium intercalation into $\mathrm{VOCl}$ electrode cannot be ignored during long cycling.

In summary, we have presented a novel room temperature Li / $\mathrm{PP}_{14} \mathrm{Cl}-\mathrm{PC} / \mathrm{VOCl}$ chloride ion battery using $\mathrm{VOCl}$ as cathode, lithium foil as anode and 1-butyl-1-methylpiperidinium chloride dissolved in propylene carbonate solvent as electrolyte. The reversible behavior of the $\mathrm{Li} / \mathrm{PP}_{14} \mathrm{Cl}-\mathrm{PC} / \mathrm{VOCl}$ cell was characterized by $\mathrm{CV}$ and galvanostatic measurements. The results show that the battery can be well discharged and recharged even at a high current density. The cell shows a first discharge capacity of $189 \mathrm{mAh} \mathrm{g}^{-1}$ at $0.5 \mathrm{C}$, corresponding to $0.72 \mathrm{~mol}$ of electrons transferred in the reaction. A discharge capacity of $113 \mathrm{mAh} \mathrm{g}^{-1}$ was obtained at $2 \mathrm{C}$ with a coulombic efficiency of $98 \%$ during 100 cycles. The mechanism of the $\mathrm{Li} /$ $\mathrm{PP}_{14} \mathrm{Cl}-\mathrm{PC} / \mathrm{VOCl}$ chloride ion battery was validated by ex-situ XRD, TEM, FTIR and XPS measurements. The results indicated that the chloride ion indeed shuttles between the cathode and anode.

\section{Acknowledgements}

Financial support from China Scholarship Council (CSC) (P.G.) and through the EU project Hi-C in FP 7, grant \# 608575, (X.M) is gratefully acknowledged. The authors thank Nina Laszczynski, Helmholtz Institute Ulm, for the lithium anode XRD measurement and the Helmholtz large scale user facility Karlsruhe Nano Micro Facility (KNMF) for access to the TEM. C.V and X. M thank Dr. Christian Kübel and Prof. Dr. Horst Hahn for their continuous support.

Keywords: chloride ion battery • electrochemistry • rechargeable $\cdot$ vanadium oxychloride

[1] X. Zhao, S. Ren, M. Bruns, M. Fichtner, J. Power Sources 2014, 245, 706-711.

[2] X. Zhao, Z. Zhao-Karger, D. Wang, M. Fichtner, Angew. Chem. Int. Ed. Engl. 2013, 52, 13621-13624.

[3] X. Zhao, Q. Li, Z. Zhao-Karger, P. Gao, K. Fink, X. Shen, M. Fichtner, ACS Appl. Mater. Interfaces 2014, 6, 10997-11000.

[4] P. Gao, X. Zhao, Z. Zhao-Karger, T. Diemant, R. J. Behm, M. Fichtner, ACS Appl. Mater. Interfaces 2014, 6, 22430-22435.

[5] H. Schaefer, F. Wartenpfuhl, J. less-common Met. 1961, 3, 29-33. 
[6] N. A. Bogdanov, J. Van Den Brink, L. Hozoi, Phys. Rev. B 2011, 84, 235146-6.

[7] S. Glawion, M. Scholz, Y.-Z. Zhang, R. Valentí, T. Saha-Dasgupta, M. Klemm, J. Hemberger, S. Horn, M. Sing, R. Claessen, Phys. Rev. B 2009, 80, 155119.

[8] E. Benckiser, R. Rückamp, T. Möller, T. Taetz, A. Möller, A. A. Nugroho, T. T. M. Palstra, G. S. Uhrig, M. Grüninger, New J. Phys. 2008, 10, 121.

[9] P. Palvadeau, D. Schleich, J. Rouxel, Mat.Res.Bull. 1979, 14, 891-897.

[10] J. F. Bringley, B. A. Averill, Chem. Mater. 1990, 2, 180-186.

[11] J. F. Bringley, Jean-Marc Fabre, B. A. Averill, J. Am. Chem. Soc. 1990, 112, 4577-4579.

[12] S. M. Kauzlarih, J. L. Stanton, J. Faber, B. A. Averill, J. Am. Chem. Soc. 1986, 108, 7946-7951.

[13] R. H. Herber, Y. Maeda, Inorg. Chem. 1981, 20, 1409-1415.
[14] I. Kargina, D. Richeson, Chem. Mater. 1996, 8, 480-485.

[15] S. Clough, P. Palvadeau, J. P. Venien, J. Phys. C: Solid State Phys. 1982, 15, 641-655.

[16] L. Cario, S. Delagrange, F. Boucher, E. Faulques, P. Palvadeau, Chem. Mater. 2003, 15, 4325-4331.

[17] J. E. Phillips, R. H. Herber, Inorganic Chemistry. 1986, 25, 3081-3088.

[18] N. Schönberg, W. G. Overend, A. Munthe-Kaas, N. A. Sörensen, Acta Chem. Scand. 1954, 8, 221-225.

[19] M. Demeter, M. Neumann, W. Reichelt, Surf. Sci. 2000, 454-456, 41-44

[20] E. Hryha, E. Rutqvist, L. Nyborg, Surf. Interface Anal. 2012, 44, 1022 1025.

[21] M. Shukla, H. Noothalapati, S. Shigeto, S. Saha, Vib. Spectrosc. 2014, 75, 107-117. 


\section{COMMUNICATION}

A highly reversible rechargeable chloride ion battery is reported. The battery is based on the reversible transfer of chloride ions between the $\mathrm{VOCl}$ cathode and the lithium anode. A reversible capacity of $113 \mathrm{mAh} \mathrm{g}^{-1}$ can be retained after 100 cycles even at a high current density of $2 \mathrm{C}$ rate.

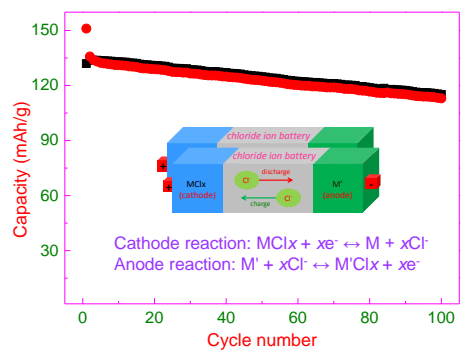

Ping Gao, M. Anji Reddy, Xiaoke Mu, Le Zhang, Zhirong Zhao-Karger,

Venkata Sai Kiran Chakravadhanula, Thomas Diemant, R. Jürgen Behm, and Maximilian Fichtner*

Page No. - Page No.

Electrochemical Investigation of VOCl for Rechargeable Chloride Ion Batteries 